\title{
EHMTI-0114. Vestibular migraine, prevalence in vestibular and headache centre and aids for diagnosis
}

\author{
C Mostardini $i^{*}$, G Nola ${ }^{2}$, R Giovanni ${ }^{3}$ \\ From 4th European Headache and Migraine Trust International Congress: EHMTIC 2014 \\ Copenhagen, Denmark. 18-21 September 2014
}

\section{Introduction}

In population-based studies, lifetime prevalence of migraine and vertigo in the general population of Western industrial nations is approximately $16 \%$ and $7 \%$, respectively. A lot terms are used to describe combination of migraine and vestibular symptoms (migranous vertigo, migraine-associated-vertigo, vertiginous migraine), recently the International Headache Society and the Barany Society (International Society for NeuroOtology) created a consensus document with diagnostic criteria for Vestibular Migraine (VM) to clearly diagnose and compare patient populations in a standardized manner.

Evaluate the prevalence of VM is particularly complex for its overlap between otolaryngology and headache experts. Our experience teaches us that, if main symptom of $\mathrm{VM}$ is headache, probably patient will be more easily diagnosed migraine but not VM, and if the main symptom is dizziness may not be interviewed on association with headache, failing the diagnosis.

Aim of the study is to start a collaboration with the otolaringology to evaluate the utility of self-administered tests to facilitate diagnosis of VM in patients who access to vestibular or headaches clinics.

\section{Methods}

Patients who access from 15 April to 30 May in our clinics will fill out self-administered tests for the diagnosis of migraine as ID-Migraine, disability scales for headache and dizziness as the Headache Impact Test 6 (HIT-6) and the Italian Dizziness Handicap Inventory (DHI-I).

\section{Results}

Preliminary data show that administration of tests has sensibly improved (more than 70\%) diagnosis of VM in vestibular and in headache clinic improving sensibility of clinicians to both symptoms, optimizing diagnosis and treatment of vertigo undefined.

No conflict of interest

\section{Authors' details}

'Neurology Department, Giovan Battista Grassi Hospital, Roma, Italy ${ }^{2}$ Otolaringology Department, Giovan Battista Grassi Hospital, Roma, Italy. ${ }^{3}$ Sapienza, University of Rome Dept of Otolaryngology, Italy.

Published: 18 September 2014

doi:10.1186/1129-2377-15-S1-B23

Cite this article as: Mostardini et al: EHMTI-0114. Vestibular migraine, prevalence in vestibular and headache centre and aids for diagnosis. The Journal of Headache and Pain 2014 15(Suppl 1):B23.

Submit your manuscript to a SpringerOpen ${ }^{\circ}$ journal and benefit from:

- Convenient online submission

- Rigorous peer review

- Immediate publication on acceptance

- Open access: articles freely available online

- High visibility within the field

- Retaining the copyright to your article

Submit your next manuscript at $\gg$ springeropen.com
(C) 2014 Mostardini et al; licensee Springer. This is an Open Access article distributed under the terms of the Creative Commons Attribution License (http://creativecommons.org/licenses/by/2.0), which permits unrestricted use, distribution, and reproduction in any medium, provided the original work is properly cited. 